\title{
Factors controlling regional grain yield in China over the last 20 years
}

\author{
Xiaobin Wang • Dianxiong Cai • Cynthia Grant • \\ Willem B. Hoogmoed • Oene Oenema
}

Accepted: 20 January 2015 / Published online: 28 April 2015

(C) INRA and Springer-Verlag France 2015

\begin{abstract}
Food production is highly dependent on regional yields of crops. Regional differences in grain yields could be due to fertilizer management and climate variability. Here, we analyze trends of grain yields in North China, Northeast China, East China, and Central and Southwest China from 1992 to 2012, using the Chinese statistical yearbooks. We estimate the major factors influencing yield by regression analysis. Results show that fertilizer indices were $40 \%$ for Northeast China, $36 \%$ for East China, $9 \%$ for North China, and $6.8 \%$ for Central and Southwest China. Soil indices were $67 \%$ for Northeast China, $14 \%$ for East China, $90 \%$ for North China, and $6 \%$ for Central and Southwest China. The indices of annual mean temperature were positive for Central and Southwest China (72\%) and East China (39\%), but negative for Northeast China $(-15 \%)$ and North China $(-16 \%)$. Soil factors explained $80 \%$ of yield variation in North China. Annual mean temperature explained $80 \%$ of yield variation in Central and Southwest China.
\end{abstract}

\footnotetext{
X. Wang $\cdot$ D. Cai $(\bowtie)$

Institute of Agricultural Resources and Regional Planning, Chinese Academy of Agricultural Sciences, Beijing 100081, China e-mail: dxcai@caas.ac.cn

$\mathrm{X}$. Wang

e-mail: xbwang@caas.ac.cn

C. Grant

Land Resource Management, Agriculture and Agri-Food Canada, Brandon Research Centre, Brandon, MB, Canada

W. B. Hoogmoed

Farm Technology Group, Wageningen University, P.O. Box 17, 6700 AA Wageningen, The Netherlands

O. Oenema

Environmental Sciences Group, Wageningen University, P.O. Box 47, 6700 AA Wageningen, The Netherlands
}

Keywords China $\cdot$ Cropland · Grain yield $\cdot$ Chemical fertilizer $\cdot$ Rainfall $\cdot$ Temperature

\section{Introduction}

A major challenge facing China is to meet the increasing food demand of its growing population in the face of decreasing arable land area and varying regional climate conditions while sustaining or improving soil productivity and avoiding adverse environmental impacts from intensive agriculture. Chemical fertilizer is an important factor influencing agricultural productivity. With recurring application of mineral fertilizers matched to yield demand, soil fertility in China has improved in terms of soil nutrient status and soil organic matter since the 1980s. According to the national agricultural subcounty data and the second national soil survey data, China's farmland quality increased gradually, with recurring application of mineral fertilizers in farmlands, from 1985 to 2008 . Over the same time period, the total area of low- and mediumyield farmlands declined from 75 to $66 \%$ (Shi et al. 2010). Although the proportions of low- and medium-yield farmlands in China have decreased under the long-term fertilizerbased intensive cropping systems, the area of low- and medium-yield farmlands is still large (about $66 \%$ ), as compared to the proportion of area of high-yield farmlands (about $34 \%$ ). It was proposed that there would be potential for increasing grain yields by improving the medium-low yield farmlands (Shi et al. 2010).

Based on statistical data, China's fertilizer consumption increased tremendously between 1980 and 2005. Total fertilizer consumption increased by about $276 \%$, while the total grain production increased by about $51 \%$ over this period (Wang et al. 2011). The average fertilizer rate per unit 
cropland in China increased from 87 to $307 \mathrm{~kg} \mathrm{ha}^{-1}$, and the average grain yields per unit cropland increased from 2734 to $4642 \mathrm{~kg} \mathrm{ha}^{-1}$ over this period. However, the fertilizer-use efficiency, expressed as grain production per unit of fertilizer applied, decreased by about $52 \%$, from 32 to $15 \mathrm{~kg} \mathrm{~kg}^{-1}$ during 1980-2005, along with a declining trend of grain yield responses to the increase in fertilizer use over time (Wang et al. 2011). Several long-term field studies also observed a reduced yield response to continuously increasing application of inorganic fertilizer alone, but not when inorganic and organic fertilizers were applied together (Huang et al. 2010). An analysis based on China statistical data suggested that the fertilizer-use efficiency could be improved by reducing regional $\mathrm{N}$ fertilizer input by at least $15 \%$ in the $\mathrm{N}$-rich regions and thus increasing regional fertilizer-use efficiency by $23 \%$, while yields in the N-poor regions could be improved by $21 \%$ through an increased $\mathrm{N}$ input of $13 \%$ (Wang et al. 2011). Other nutrient management practices, such as added organic manure or adjusted NPK nutrient input ratios, are also highly recommended (Huang et al. 2010). Rose et al. (2014), via farmer participatory research, found that using a biofertilizer can replace between 23 and $52 \%$ of nitrogen fertilizer and improve nutrient use efficiency without loss of yield in lowland rice in the Vietnamese Mekong Delta. The efforts to improving low- and medium-yield farmlands may still benefit from not only the regulation in regional nutrient management but also other factors because of regional soil problems, climate variability, management constraints linked to economic development, and increased land-use intensity (Shi et al. 2010; Zhou 2013). Therefore, the strategies and regional regulation of fertilizer management still need to be strengthened to improve yield response, reduce environmental impacts, and ensure long-term food security.

Climate is also an important factor influencing agricultural productivity. Evidence from Chinese and international sources on the impacts of observed climate trends and climate change on agriculture shows that climate change continues to have a major impact on crop productivity all over the world (Lobell and Field 2007; Li et al. 2011; You et al. 2009). Liu and Lin (2007), evaluated statistical data during 1984-2003 and reported that rapid warming as a result of climate change obviously promoted increased total crop production in Northeast China, suppressed it in North China, Northwest China, and Southwest China, but had no obvious influence in East China and Central-South China. An investigation through analysis of climate-yield relationships from 1980 to 2008 in China suggested that reduction in yields, especially for maize, with higher temperature was accompanied by lower precipitation, due to droughts, mainly in northern parts of China. In contrast, a positive correlation between temperature and yield can be explained by the effect of solar radiation accompanied by abundant water resources, mainly in the southern part of China, where interannual variations in precipitation and solar radiation have driven change in cereal yields in China over the last three decades (Zhang and Huang 2012). A number of studies using historical climate and crop data indicate that climate is affecting cereal yields in China; however, the nature of the impact of climate change on crop yields in China is still not clear. These studies in China are generally either focused on a single aspect of the interactions between climate change and food production or are performed in specific small regions. At the same time, straightforward assessments of climate change impacts on crop yields by crop growth models ignore the adaptation of farmers to climate change through crop choice and management (Wu et al. 2014). Recently, Ye et al. (2013), using crop models to simulate the effect of further climate change on food security in China during 2030 2050 , predicts that climate change only has a moderate positive effect on food security as compared to other factors such as cropland area, population growth, socio-economic pathway, and technology development. However, more attention is needed on food safety and balanced nutrition issues in order to ensure food security in China over the long run (Ye et al. 2013). Therefore, it is important to understand the impacts of a continuous rise in fertilizer use and annual climate variability in rainfall and mean temperature on regional yield differences and yield trends, and the implications that these effects may have for increasing yield potential in the main food production regions of China.

In China's 31 provinces, autonomous regions, and municipalities directly under the central government, there are 13 major grain-producing regions. According to national statistical data in 2012 (National Bureau of Statistics of China (NBSC) 2013), the total major grain (including rice, wheat, and maize crops) production accounted for about $90 \%$ of the national total grain production. The major grain production in the top 13 major grain-producing provinces accounted for $77 \%$ of the national total major grain production, accounting for about $10,19,24$, and $25 \%$ of the national total, respectively, for North China, Northeast China, East China, and Central and Southwest China (Ministry of Agriculture of China (MOAC) 2009). Figure 1 shows field pictures of maize, wheat, and rice crops in China.

We hypothesize that, in the fertilizer-based intensive cropping systems in China, the changes in regional grain yields or yield responses have been affected not only by fertilizer use but also by annual climate variability, such as changes in annual rainfall and annual mean temperature, over time, during the last 20 years.

This paper, based on China Statistical Yearbooks 19932013, analyzes regional yield differences associated with regional fertilizer use and annual climate variability in rainfall and mean temperature, over the last 20 years, and assesses the relative contributions of yield-influencing factors, including fertilizer, soil-related factors, climate variability, and temporal variability, in the major grain-producing regions in North 


\section{(a) Summer maize field in Hebei (maize maturity)}

\section{(b) Winter wheat field in Henan (wheat maturity)}

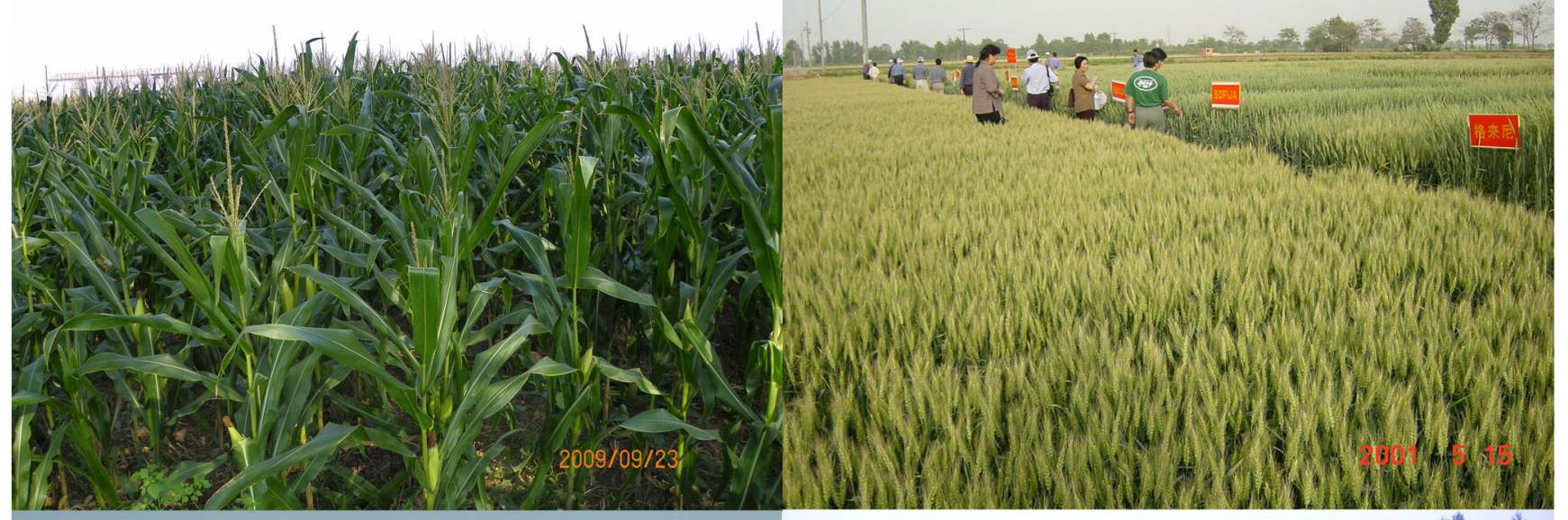

(c) Rice field in Jiansu (rice transplanting)

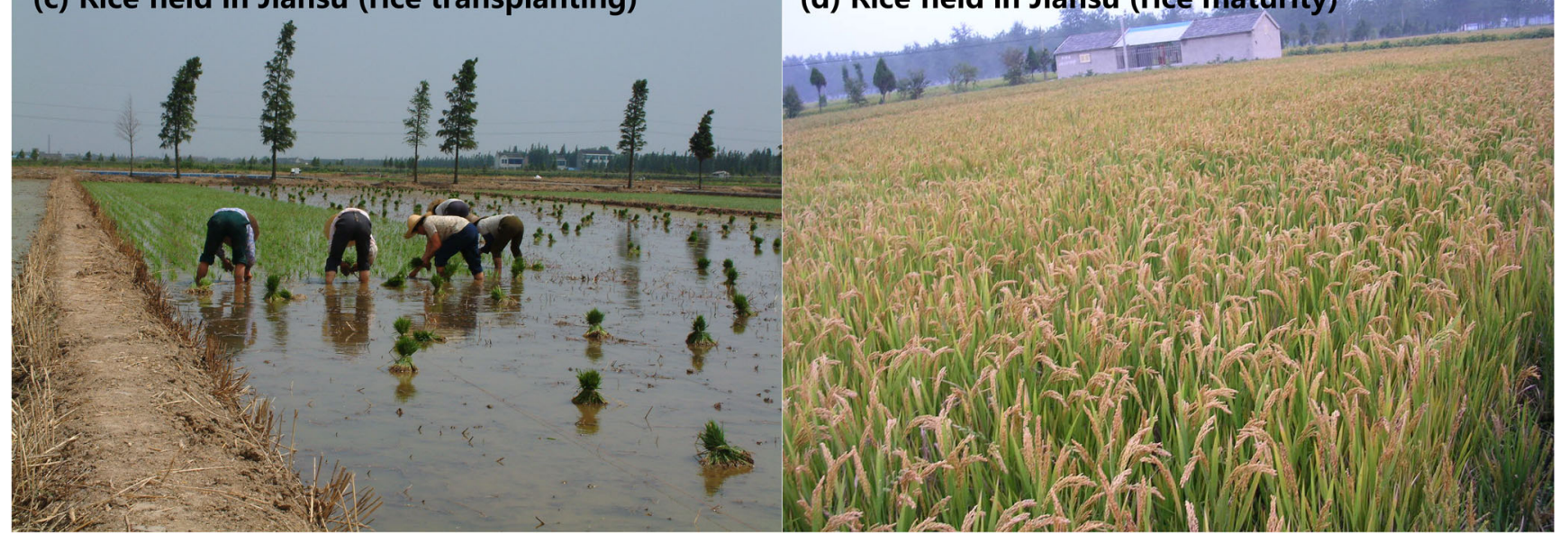

Fig. 1 Fields of maize, wheat, and rice crops in China: a summer maize field in Hebei (in North China), b winter wheat field in Henan (in Central China), and $\mathbf{c}, \mathbf{d}$ rice fields in Jiangsu (in East China)

China, Northeast China, East China, and Central and Southwest China. The aim of the study is to gather useful information to guide regional fertilizer management practices that can further help enhance regional grain yields under varying regional climate conditions to meet the grand challenge of food production security and sustainable development.

\section{Materials and methods}

\subsection{Site description}

The research sites were located in the 13 major grainproducing provinces of China, distributed in the following four regions: (1) North China (Hebei and Inner Mongolia), (2) Northeast China (Heilongjiang, Jilin, and Liaoning), (3) East China (Anhui, Jiangsu, Jiangxi, and Shandong), and (4) Central and Southwest China (Henan, Hubei, Hunan, and Sichuan provinces) (shown in Fig. 2).

\subsection{Data collection and analysis}

The statistical data including fertilizer inputs, major grain yields, and annual climate data in the four regions involved in the 13 grain-producing provinces for the period 1992 2012 were gathered from the China Statistical Yearbooks (National Bureau of Statistics of China (NBSC) 19932013). Data for fertilizer inputs include the total NPK $\left(\mathrm{N}+\mathrm{P}_{2} \mathrm{O}_{5}+\mathrm{K}_{2} \mathrm{O}\right)$ nutrient inputs from nitrogenous, phosphate, potash, and compound fertilizer. Data for major grain yields include the total grain yields of three grain crops, including rice, wheat, and maize. Data for annual climate variability include the data of annual rainfall and annual mean temperature. The data for regional fertilizer use in the three major grain crops were also collected from the National Farm Product Cost-Benefit Survey issued by the National Development and Reform Commission (NDRC) 1993-2013). The data were used to analyze the trends in regional grain yields associated with the fertilizer use and annual climate variability in rainfall and mean 


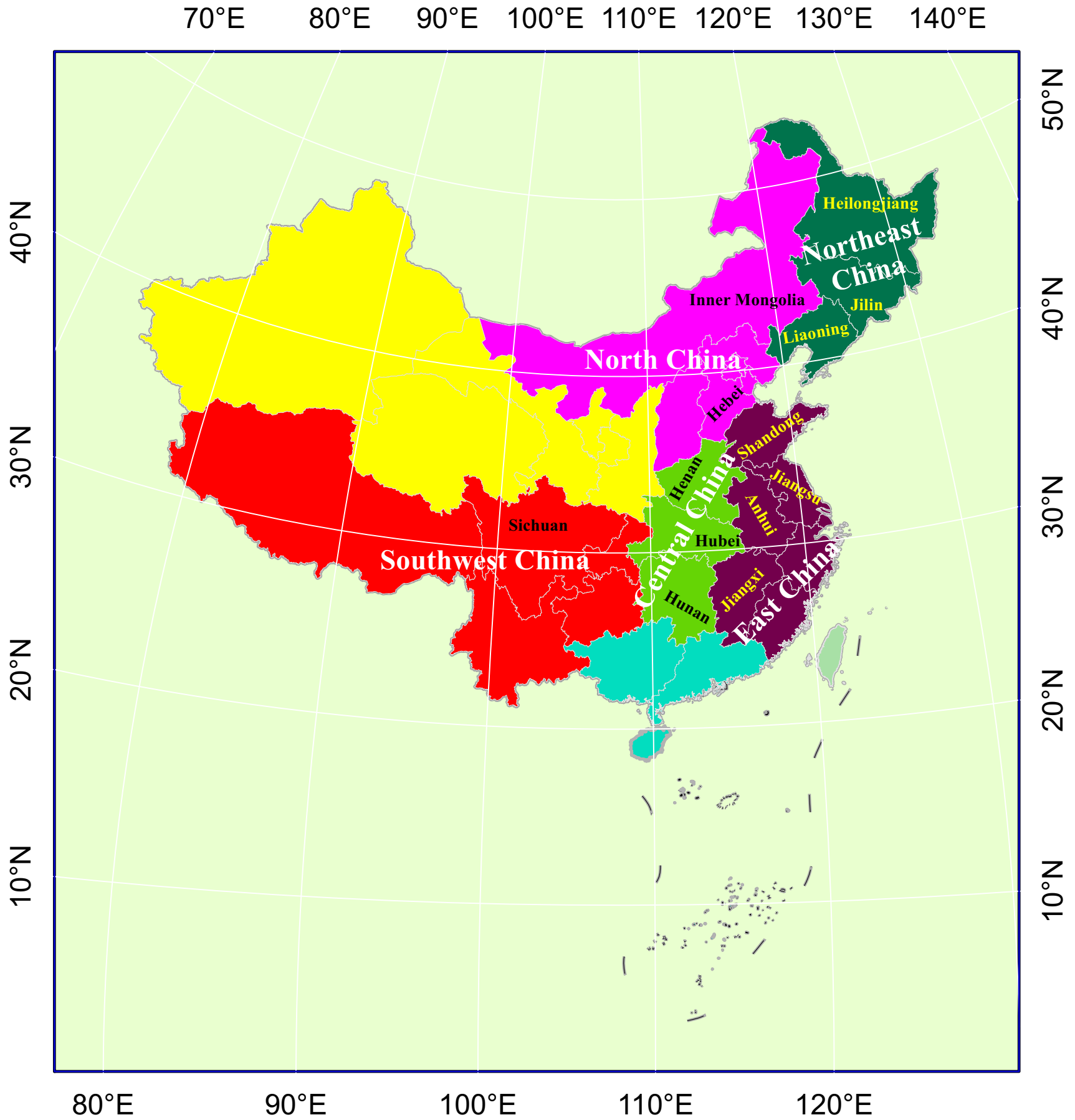

Fig. 2 Map of the research sites in the 13 major grain-producing provinces in China in four regions: (1) North China: Hebei, and Inner Mongolia; (2) Northeast China: Heilongjiang, Jilin, and Liaoning; (3)

East China: Anhui, Jiangsu, Jiangxi, and Shandong; and (4) Central and Southwest China: Henan, Hubei, Hunan, and Sichuan provinces

temperature, over the last 20 years. They were also used to estimate the relative contributions of fertilizer use and climate variability in annual rainfall and annual mean temperature, as well as other factors, such as a soil-related factor and a year-time variable, to regional grain yields, based on the statistical models.

\subsection{Calculations and estimations}

Indices included grain yield, and relative contributions to yields derived from fertilizer, annual rainfall, annual mean temperature, soil-related factors, and year-time variable, respectively, calculated or estimated by the statistical models. 
Statistical analysis was conducted using the REG procedure of the SAS Institute, Inc. (2004). Multiple linear regression models were fitted to describe the relationships between regional grain yield and added fertilizer, annual rainfall, annual mean temperature, and year-time variable. The regional grain yield was calculated as function of fertilizer, annual rainfall, annual mean temperature, and year-time variable, as follows.

$$
\begin{aligned}
\mathrm{GY}= & b_{0}+b_{1} \times F+b_{2} \times \mathrm{AR}+b_{3} \times \mathrm{AMT}+b_{4} \\
& \times \mathrm{YR}
\end{aligned}
$$

Where

$\begin{array}{ll}\mathrm{GY} & \text { grain yields }\left(\mathrm{kg} \mathrm{ha}^{-1}\right) \\ F & \text { fertilizer rate }(\mathrm{NPK} \text { nutrient } \\ & \text { input rate) }\left(\mathrm{kg} \mathrm{ha}^{-1}\right) \\ \text { AR } & \text { annual rainfall }(\mathrm{mm}) \\ \text { AMT } & \text { annual mean temperature }\left({ }^{\circ} \mathrm{C}\right) \\ \text { YR } & \text { time (year) } \\ b_{0}, b_{1}, b_{2}, b_{3}, \text { and } b_{4} & \text { coefficients. }\end{array}$

Finally, the relative contributions of fertilizer use and climate variability in annual rainfall, and annual mean temperature as well as other factors, such as soil-related factors, and year-time variable to regional grain yields were analyzed, based on the statistical models. The percentage of grain yields derived from fertilizer use, annual rainfall, annual mean temperature, soil-related factors, and year-time variable, respectively, can be calculated to estimate the relative contributions to yields derived from these factors.

\section{Results and discussion}

3.1 Trends in regional grain yields, fertilizer use, and annual climate variability

Based on China Statistical Yearbooks (National Bureau of Statistics of China (NBSC) 1993-2013), the annual climate variability in rainfall, and mean temperature, major grain sown area, fertilizer use in major grain cropland and fertilizer rate per unit grain cropland, and major grain production and grain yield per unit grain cropland in the major grain yieldproducing regions over the last 20 years (1992-2012) are shown in Fig. 3. The annual rainfall changed insignificantly from 1992 to 2012, with average rates of change of 1.0, 3.3, 0.23 , and $-4.7 \mathrm{~mm}$ year $^{-1}$, corresponding to an average annual rainfall of 461, 590, 1117, and $1042 \mathrm{~mm}$, respectively, for North China, Northeast China, East China, and Central and Southwest China. The annual mean temperature changed from 1992 to 2012, with average rates of change of 0.029 , $-0.0082,0.015$, and $0.033{ }^{\circ} \mathrm{C}_{\text {year }}{ }^{-1}$, corresponding to an average annual mean temperature of $11.0,6.7,16.5$, and $16.7^{\circ} \mathrm{C}$, respectively, for North China, Northeast China, East China, and Central and Southwest China (but not significantly).

The major grain sown areas for North China, Northeast China, East China, and Central and Southwest China changed by about 32, 63, 4, and $-5 \%$, respectively, from 1992 to 2012 , while the major grain production for North China, Northeast China, East China, and Central and Southwest China increased by about $91,111,31$, and $21 \%$, respectively, from 1992 to 2012, showing that the changes in the regional major grain production were significantly influenced by the changes in regional major cropland area for the four regions (Fig. 3). Correspondingly, the fertilizer use in major grain cropland increased by about $115,101,31$, and $46 \%$, respectively, during the same period. Date showed that the major grain production for North China, Northeast China, East China, and Central and Southwest China increased by about 40, 30, 10, and $1 \%$, respectively, from 1992 to 1998 , but decreased by $15,22,19$, and $13 \%$, respectively, from 1998 to 2003, and then increased by $62,107,48$, and $38 \%$, respectively, from 2003 to 2012 (Fig. 3). Correspondingly, the fertilizer use in major grain cropland for North China, Northeast China, East China, and Central and Southwest China increased by about $61,22,27$, and $15 \%$, respectively, from 1992 to 1998 , but decreased by $10,21,17$, and $10 \%$, respectively, from 1998 to 2003 , and then increased by $49,109,24$, and $41 \%$, respectively, from 2003 to 2012 (Fig. 3). The results indicated that the fertilizer use in major grain cropland increased for North China and Central and Southwest China (by 115 and $46 \%$, respectively) faster than the increase in major grain production (by 91 and $21 \%$, respectively) during 1992-2012, especially during 1992-1998. Data on yield trend analysis from others (Xin et al. 2012) also showed that China's grain yield per unit area reached record highs in 1998, but has stagnated since then; this was mainly attributed to the rapidly growth in agricultural fertilizer consumption since the end of the 1980s.

The regional fertilizer rates per unit grain cropland on weighted average changed from 198 to 324,217 to 268,302 to 379 , and 245 to $379 \mathrm{~kg} \mathrm{ha}^{-1}$, respectively, for North China, Northeast China, East China, and Central and Southwest China during 1992-2012, corresponding to average increase rates of $4.8\left(R^{2}=0.79\right), 1.3\left(R^{2}=0.19\right), 2.4\left(R^{2}=0.26\right)$, and $6.0\left(R^{2}=\right.$ $0.80) \mathrm{kg} \mathrm{ha}^{-1}$ year $^{-1}$ (Fig. 3). The changes in regional grain yields per unit grain cropland on weighted average from 1992 to 2012 significantly increased from 3859 to 5600,5123 to 6636,4885 to 6160 , and 4752 to $6060 \mathrm{~kg} \mathrm{ha}^{-1}$, respectively, for North China, Northeast China, East China, and Central and Southwest China, corresponding to average increase rates of $70,53,52$, and $63 \mathrm{~kg}_{\text {year }}{ }^{-1}$. The grain yields per unit grain cropland for North China, Northeast China, East China, and Central and Southwest China increased by about 45, 30, 26, and $28 \%$, respectively, from 1992 to 2012, correspondingly, 


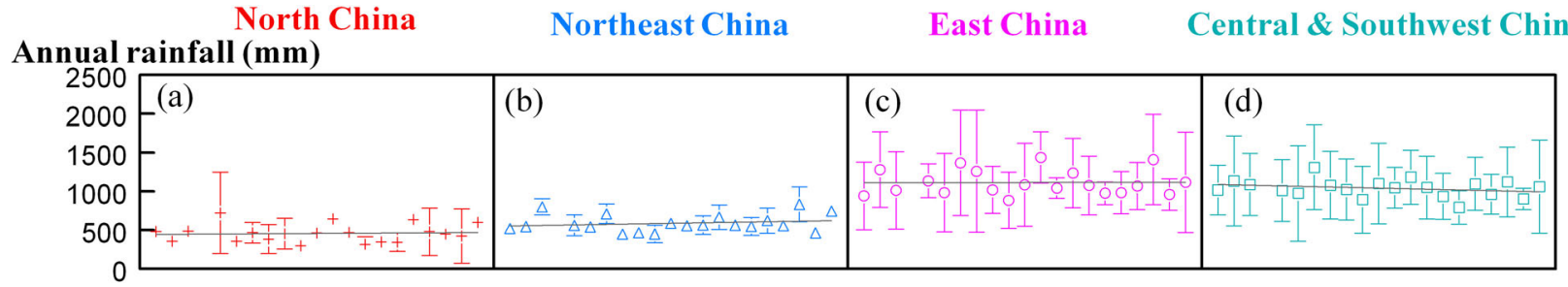

Mean temperature $\left({ }^{\circ} \mathrm{C}\right)$

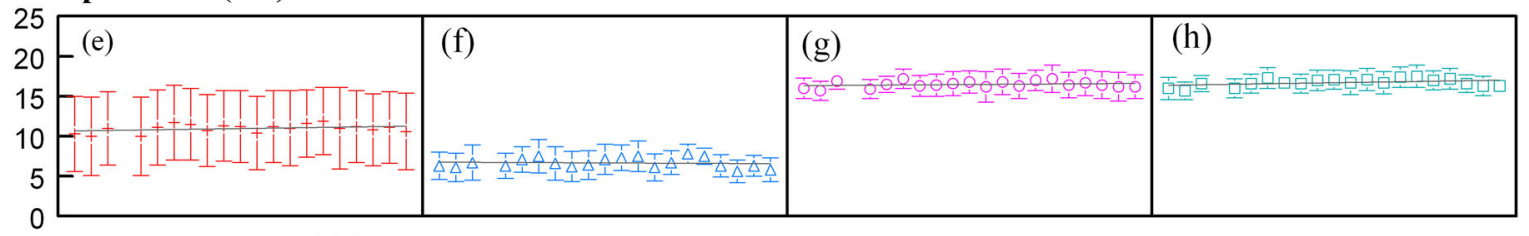

Major grain sown area (1000 ha)

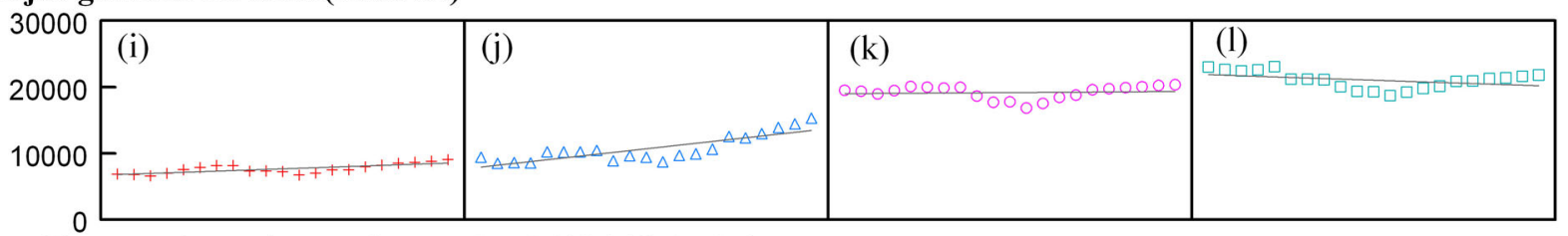

Fertilizer use in major grain cropland $(10000 \mathrm{t})$ - left

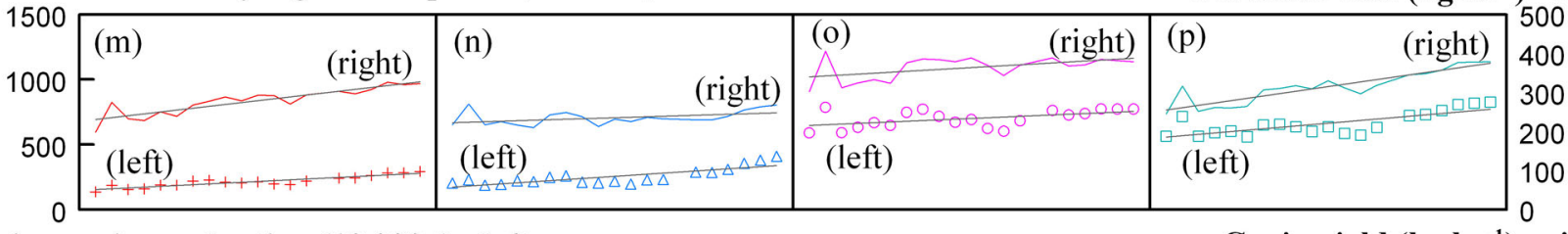

Major grain production (10 $000 \mathrm{t})$ - left

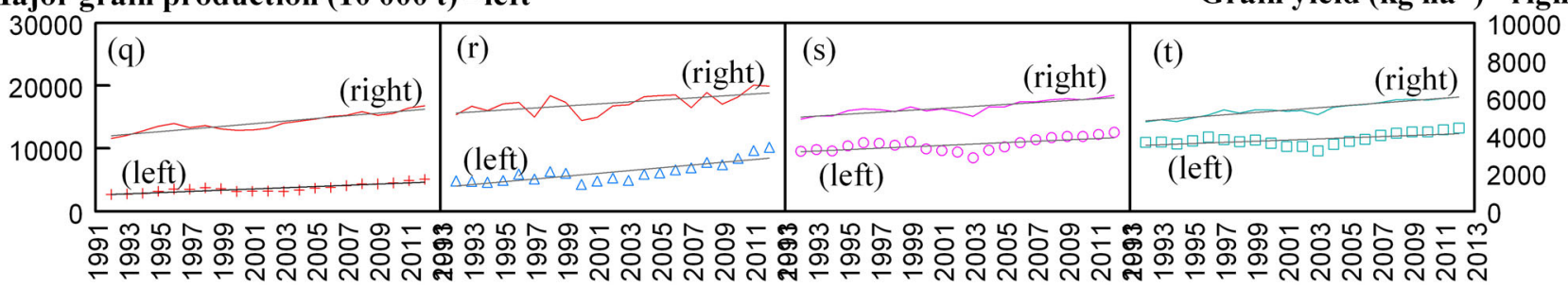

Time (Year)

Fig. 3 Trends in (1) annual rainfall $(A R, \mathrm{~mm}),(2)$ annual mean temperature $\left(A M T,{ }^{\circ} \mathrm{C}\right),(3)$ major grain sown area $(M G A, 1000$ ha), (4) fertilizer use in major grain cropland $(M G F, 10,000 \mathrm{t})$ and fertilizer rate $\left(F, \mathrm{~kg} \mathrm{ha}^{-1}\right)$, and (5) major grain production $(M G P, 10,000 \mathrm{t})$ and grain yield $\left(G Y, \mathrm{~kg} \mathrm{ha}^{-1}\right)$ in North China, Northeast China, East China, and Central and Southwest China over the last 20 years (Source: National Bureau of Statistics of China (NBSC) 1993-2013). Regression equations: (1) for annual rainfall (a-d): $\operatorname{AR}(\mathrm{a})=1.0 x-1551\left(R^{2}=\right.$ $0.0028), \operatorname{AR}(\mathrm{b})=3.25 x-5925\left(R^{2}=0.032\right), \mathrm{AR}(\mathrm{c})=0.23 x+652\left(R^{2}=8 \mathrm{E}\right.$ $-05)$, and $\mathrm{AR}(\mathrm{d})=-4.73 x+10,512\left(R^{2}=0.066\right)$; (2) for annual mean temperature $(\mathbf{e}-\mathbf{h})$ : $\operatorname{AMT}(\mathrm{e})=0.029 x-47.8\left(R^{2}=0.11\right), \operatorname{AMT}(\mathrm{f})=$ $-0.0082 x+23.0\left(R^{2}=0.0063\right)$, AMT $(\mathrm{g})=0.015 x-13.8\left(R^{2}=0.05\right)$, and AMT $(\mathrm{h})=0.033 x-49.6\left(R^{2}=0.17\right)$; (3) for major grain sown area $(\mathbf{i}-\mathbf{l})$ :

the fertilizer rates per unit grain cropland increased by about $63,23,26$, and $55 \%$, respectively, during the same period (Fig. 3). However, the fertilizer rates per unit grain cropland increased faster than the increase in grain yields during 19922012 for North China, and Central and Southwest China, showing an unbalanced input-output for grain production in these regions, but not for Northeast China and East China.
$\operatorname{MGA}(\mathrm{i})=85.6 x+6731\left(R^{2}=0.53 *\right), \operatorname{MGA}(\mathrm{j})=275 x+1924\left(R^{2}=0.68^{* *}\right)$, $\operatorname{MGA}(\mathrm{k})=15.8 x+18,384\left(R^{2}=0.009\right)$, and $\operatorname{MGA}(\mathrm{l})=-83.4 x+27,248$ $\left(R^{2}=0.16\right)$; (4) for fertilizer use in major grain cropland and fertilizer rate $(\mathbf{m}-\mathbf{p}): \operatorname{MGF}(\mathrm{m})=6.22 x+148\left(R^{2}=0.82^{* *}\right)$ and $\mathrm{F}(\mathrm{m})=4.81 x+226$ $\left(R^{2}=0.79^{* *}\right), \operatorname{MGF}(n)=8.35 x-11.2\left(R^{2}=0.66^{* *}\right)$ and $\mathrm{F}(\mathrm{n})=1.26 x+222$ $\left(R^{2}=0.19\right), \operatorname{MGF}(\mathrm{o})=5.43 x+413\left(R^{2}=0.26\right)$ and $\mathrm{F}(\mathrm{o})=2.40 x+338\left(R^{2}=\right.$ $0.26)$, and $\operatorname{MGF}(\mathrm{p})=10.7 x-129\left(R^{2}=0.57^{* *}\right)$ and $\mathrm{F}(\mathrm{p})=6.01 x+249\left(R^{2}=\right.$ $0.80 * *) ;(5)$ for major grain production and grain yield $(\mathbf{q}-\mathbf{t})$ : $\operatorname{MGP}(\mathrm{q})=$ $95.8 x+2583\left(R^{2}=0.77^{* *}\right)$ and $\mathrm{GY}=70.1 x+3935\left(R^{2}=0.85^{* *}\right), \mathrm{MGP}(\mathrm{r})=$ $222 x-885\left(R^{2}=0.69^{* *}\right)$ and $\mathrm{GY}(\mathrm{r})=53.0 x+5167\left(R^{2}=0.40 *\right), \mathrm{MGP}(\mathrm{s})=$ $112 x+4690\left(R^{2}=0.42 *\right)$ and $\mathrm{GY}(\mathrm{s})=52.0 x+4940\left(R^{2}=0.79 * *\right)$, and $\operatorname{MGP}(\mathrm{t})=94.0 x+4466\left(R^{2}=0.39\right)$ and $\mathrm{GY}(\mathrm{t})=63.2 x+4730\left(R^{2}=0.91^{* *}\right)$

With China's large size and range of agro-ecological conditions, ecosystem sensitivity and exposure can vary considerably, leading to complex spatial patterns of response ( $\mathrm{Li}$ et al. 2011). Our results for the four regions showed yield variability in both temporal and spatial variability, due to regional differences in fertilizer input, annual rainfall, and annual mean temperature. As described previously, the increasing 
trends and differences in regional grain yields in the four regions over the last 20 years were mainly associated with increased fertilizer use over time, while the average fertilizer increase rates (in $\mathrm{kg} \mathrm{ha}^{-1} \mathrm{year}^{-1}$ ) were in the order of Central and Southwest China (6.0) $>$ North China (4.8) $>$ East China (2.4) $>$ Northeast China (1.3). Results showed that both the fertilizer use in major grain cropland and fertilizer rates per unit grain cropland increased for North China, and Central and Southwest China faster than the increase in both the major grain production and grain yield per unit grain cropland during 1992-2012, especially during 1992-1998; however, the increase in fertilizer use for Northeast China was slower than the increase in grain yield during the same period. Machado et al. (2002) reported that managing factors that influence the temporal variability of crop yields is a major challenge to farmers because temporal variation reflects variation in precipitation, soil moisture, nutrient status, disease, and pests in time and is very difficult to predict. Huggins and Alderfer (1995) reported that temporal variability explained more than $50 \%$ of crop yield variability across years and sites in corn. Eghball and Varvel (1997) found that temporal variability was more important than management (i.e., $\mathrm{N}$ fertilizer and cropping sequences). Girma et al. (2007) also found that temporal variability due to yield-limiting factors other than $\mathrm{N}$ is a major factor controlling winter wheat grain yield, followed by $\mathrm{N}$ fertilizer. This observation supports the current notion that "average based" $\mathrm{N}$ recommendation should be avoided and suggests a shift to alternate strategies for managing temporal variability. Crop management practices that do not attempt to control or minimize the effects of both temporal and spatial variability are incomplete and can have large detrimental economic effects for producers (Girma et al. 2007); hence, improvements in the control and management of site-specific farming, especially some temporal effects, may lead to substantial gains in grain yield and profitability (Machado et al. 2002).

\subsection{Regional grain yields in responses to fertilizer use} and annual climate variability

The regional yield responses to fertilizer use from 1992 to 2012 were significantly positive for Northeast China and East China, but not for North China and Central and Southwest China, correspondingly, with average rates of change of 7.8 $\left(R^{2}=0.48\right), 4.2\left(R^{2}=0.37\right), 1.7\left(R^{2}=0.079\right)$, and $2.0\left(R^{2}=\right.$ $0.066) \mathrm{kg} \mathrm{ha}^{-1}$ (Fig. 4). The regional yield responses to climate variability in annual rainfall and annual mean temperature were small but significant for Central and Southwest China (Fig. 4). The grain yield for Central and Southwest China was positively correlated with the increase in both annual rainfall $\left(R^{2}=0.27\right)$ and annual mean temperature $\left(R^{2}=0.48\right)$, indicating that annual climate variability had a greater influence on grain yields for Central and Southwest China than the fertilizer use $\left(R^{2}=0.066\right)$.

The statistical analysis of annual variations in grain yields by regions in response to added fertilizer, annual rainfall, and annual mean temperature, as well as year-time variable for the period 1992-2012 is shown in Table 1. The statistical models could satisfactorily explain the increasing trends in regional grain yields over the last 20 years, in response to fertilizer application rates, annual rainfall, annual mean temperature, and year-time variable, accounting for about $80,59,61$, and $80 \%$ of yield variability, respectively, for regions North China, Northeast China, East China, and Central and Southwest China (Table 1). During 1992-2012, the regional grain yields and fertilizer added were significantly positively correlated for Northeast China, East China, and Central and Southwest China with regression model coefficients of 9.3, 5.7, and $1.2 \mathrm{~kg} \mathrm{~kg}^{-1}$, respectively, but less correlated for North China (1.7). The regional fertilizer use on weighted average increased from 217 to 268,302 to 379,198 to 324 , and 245 to $379 \mathrm{~kg} \mathrm{ha}^{-1}$, respectively, for Northeast China, East China, and Central and Southwest China and North China during the same period, corresponding to average increase rates of $1.3,2.4,4.8$, and $6.0 \mathrm{~kg} \mathrm{ha}^{-1}$ year $^{-1}$ (Fig. 3).

Changes in regional grain yields were not significantly affected by annual variations in annual rainfall, except for Central and Southwest China $(P<0.0001)$. The regional grain yields and annual mean temperature were significantly positively correlated for Central and Southwest China, and East China with coefficients of 237 and $128 \mathrm{~kg}^{\circ} \mathrm{C}^{-1}$, respectively, but less correlated for North China and Northeast China, indicating that grain yields in some regions might be more sensitive to annual climate variability in annual rainfall, or annual mean temperature than to fertilizer added, especially for Central and Southwest China. It may be that fertilizer supply became less limiting over time in Central and Southwest China due to increases in residual nutrient resulting from the continuous increase in fertilizer use over time. The increasing trend in grain yields with increased fertilizer use over time in the four regions over the last 20 years was significantly related to the year-time variable (Table 1), with coefficients of 71, 34, 38, and $46 \mathrm{~kg} \mathrm{year}^{-1}$, respectively, for North China, Northeast China, East China, and Central and Southwest China, indicating that annual variations in regional grain yields may also be attributed to other factors, probably to increased soil fertility or water availability related to improved farming practices.

Over the last 20 years, fertilizer use in China has rapidly increased to meet the increasing food demand of its growing population. Fertilizer use plays an irreplaceable role in China's food production, resulting in a $50 \%$ increase in the total grain production in China (Wang et al. 2011). However, several long-term field studies have observed a reduced yield 


\section{Grain yield (kg ha $\left.{ }^{-1}\right)$}

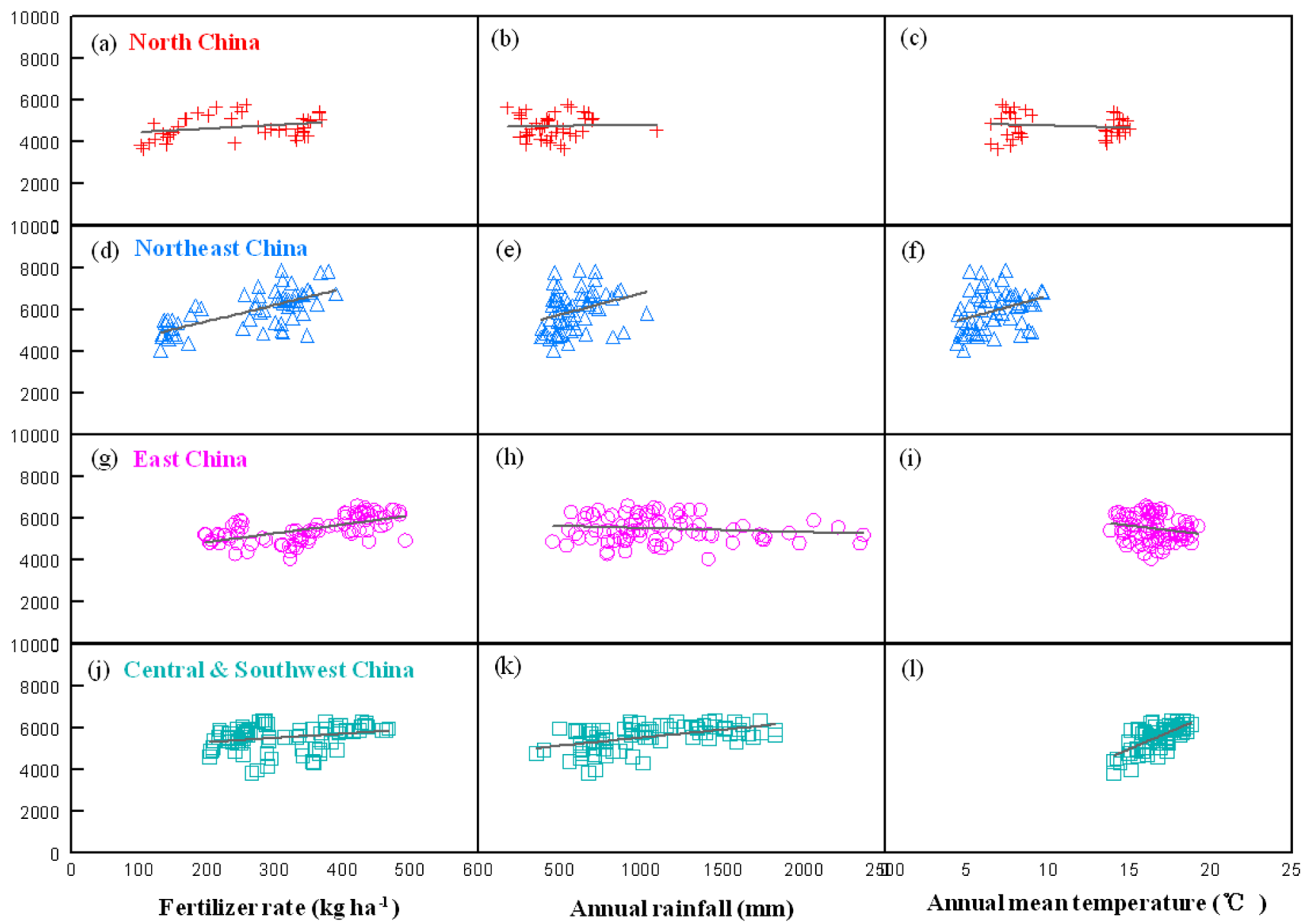

Fig. 4 Regional grain yields $(G Y)$, in responses to fertilizer use $(F)$, annual rainfall $(A R)$, and annual mean temperature $(A M T)$ in North China, Northeast China, East China, and Central and Southwest China for the period 1992-2012. Regression equations for North China $(\mathbf{a}-\mathbf{c})$ : $\mathrm{GY}(\mathrm{a})=1.72 F+4277\left(R^{2}=0.079\right) ; \mathrm{GY}(\mathrm{b})=0.094 \mathrm{AR}+4704\left(R^{2}=\right.$ $0.0008)$; GY(c) $=-19.8 \mathrm{AMT}+4964\left(R^{2}=0.014\right)$; for Northeast China

response to continuously increasing chemical fertilizer use (Huang et al. 2010). Previous analysis showed that the growth rate of grain yields was closely related to the increase in fertilizer use during 1980-1985, while there was a declining trend of yield response to the increase in fertilizer use over the subsequent time period (1985-2005), and an increasing number of regions with little or no yield response to changes in fertilizer rate over time after the 1990s (Wang et al. 2011). As our results indicated, regional yield responses to fertilizer added were positive (Table 1) over time, while they were higher for Northeast China and East China, as compared to North China and Central and Southwest China, with regression model coefficients (in $\mathrm{kg} \mathrm{kg}^{-1}$ ) of 9.3, 5.7, 1.7, and 1.2, respectively, for Northeast China, East China, North China, and Central and Southwest China. In the fertilizer-based intensive cropping systems, fertilizer-use management has been a major limiting factor in China's agricultural sustainable $(\mathbf{d}-\mathbf{f}): \mathrm{GY}(\mathrm{d})=7.77 F+3871\left(R^{2}=0.48^{* *}\right) ; \mathrm{GY}(\mathrm{e})=2.01 \mathrm{AR}+4735\left(R^{2}=\right.$ $0.09)$; and $\mathrm{GY}(\mathrm{f})=208 \mathrm{AMT}+4534\left(R^{2}=0.11\right)$; for East China $(\mathrm{g}-\mathbf{i})$ : $\mathrm{GY}(\mathrm{g})=4.22 F+4011\left(R^{2}=0.37 * *\right) ; \mathrm{GY}(\mathrm{h})=-0.19 \mathrm{AR}+5723\left(R^{2}=\right.$ $0.018)$; GY(i) $=-90.7 \mathrm{AMT}+7000\left(R^{2}=0.039\right)$; and for Central and Southwest China $(\mathbf{j}-\mathbf{l}): \mathrm{GY}(\mathrm{j})=2.02 F+4895\left(R^{2}=0.066\right) ; \mathrm{GY}(\mathrm{k})=$ $0.77 \mathrm{AR}+4742\left(R^{2}=0.27^{*}\right)$; and $\mathrm{GY}(1)=333 \mathrm{AMT}-8.57\left(R^{2}=0.48^{* *}\right)$

development. Experts suggest that intensive use of arable land will be required in the future to ensure food security in China (Zhou 2013), but it must be coupled to sustained soil productivity and environmental quality.

Many studies in China showed that climate variability may produce either positive or negative effects on crop yield depending on regional conditions and crop varieties (Piao et al. 2010). A recent study on regional-scale yield-temperature relationships, using gridded climate and observed crop yield data since 1980 in China, shows considerable reductions in spring wheat yield in the central Northeast, winter wheat in the Yellow River basin, and maize in Southwest China in response to increasing temperature. However, in most of the main food-producing areas, crop yields have either remained constant or increased over this period due to better agronomic management (Xiong et al. 2014). Lin et al. (2008) reported that higher temperatures were beneficial to agricultural 
Table 1 Coefficients of the regression models for regional major grain yields, as function of fertilizer rate (F), annual rainfall (AR), annual mean temperature (AMT), and year-time variable (YR), in North China,
Northeast China, East China, and Central and Southwest China for the period 1992-2012 (Source: National Bureau of Statistics of China (NBSC) 1993-2013)

\begin{tabular}{|c|c|c|c|c|c|c|}
\hline Region & Parameters & Intercept & $F$ & $\mathrm{AR}$ & AMT & YR \\
\hline \multicolumn{7}{|l|}{ North China } \\
\hline \multirow[t]{4}{*}{$\left(R^{2}=0.80 *, N=37\right)$} & PE & 4218 & 1.69 & 0.21 & -67.8 & 71.1 \\
\hline & SE & 210 & 1.74 & 0.27 & 43.2 & 11.4 \\
\hline & $t$ value & 20.1 & 0.97 & 0.81 & -1.57 & 6.25 \\
\hline & $\operatorname{Pr}>|t|$ & $<.0001$ & 0.34 & 0.43 & 0.13 & $<.0001$ \\
\hline \multicolumn{7}{|l|}{ Northeast China } \\
\hline \multirow[t]{4}{*}{$\left(R^{2}=0.59^{*}, N=56\right)$} & $\mathrm{PE}$ & 3912 & 9.29 & 0.21 & -136.2 & 34.1 \\
\hline & SE & 461 & 1.42 & 0.65 & 76.8 & 14.2 \\
\hline & $t$ value & 8.48 & 6.53 & 0.32 & -1.77 & 2.39 \\
\hline & $\operatorname{Pr}>|t|$ & $<.0001$ & $<.0001$ & 0.75 & 0.08 & 0.02 \\
\hline \multicolumn{7}{|l|}{ East China } \\
\hline \multirow[t]{4}{*}{$\left(R^{2}=0.61^{*}, N=75\right)$} & PE & 772 & 5.69 & 0.21 & 128.2 & 38.0 \\
\hline & SE & 1083 & 0.80 & 0.15 & 57.8 & 7.86 \\
\hline & $t$ value & 0.71 & 7.08 & 1.44 & 2.22 & 4.83 \\
\hline & $\operatorname{Pr}>|t|$ & 0.48 & $<.0001$ & 0.15 & 0.03 & $<.0001$ \\
\hline \multicolumn{7}{|c|}{ Central and Southwest China } \\
\hline \multirow[t]{4}{*}{$\left(R^{2}=0.80^{*}, N=75\right)$} & $\mathrm{PE}$ & 348 & 1.21 & 0.39 & 236.8 & 45.7 \\
\hline & SE & 561 & 0.45 & 0.11 & 35.8 & 5.68 \\
\hline & $t$ value & 0.62 & 2.69 & 3.67 & 6.62 & 8.04 \\
\hline & $\operatorname{Pr}>|t|$ & 0.54 & 0.009 & 0.0005 & $<.0001$ & $<.0001$ \\
\hline
\end{tabular}

$P E$ parameter estimate, $S E$ standard error, $\operatorname{Pr}$ probability value ( $P$ value)

production in Heilongjiang province in the absence of drought or meteorological disasters and that the change in precipitation did not necessarily affect crop yields. He indicated that fertilizer was the leading driving economic force that had steadily increased grain yields in the whole Heilongjiang province over the 15-year period from 1986 to 2000 . Therefore, it is necessary to include such major factors as physical inputs into the crop yield-climate function to accurately estimate climate impact on crop yields and to distinguish the effect of climate from other crop yield drivers (You et al. 2009).

\subsection{Analysis of relative contributions of yield-influencing factors}

Further analysis of the relative contributions of major yieldinfluencing factors, including soil-related factors, fertilizer rate, annual rainfall, annual mean temperature, and year-time variable, respectively, using the percentage of grain yields derived from these factors, based on multiple linear regressions (Table 1). The results averaged over 1992-2012 (in Table 2) showed that for the indices of factors influencing yields, the indices of soil-related factors were in the orders of North China $(90 \%)>$ Northeast China $(67 \%)>$ East China $(14 \%)>$ Central and Southwest China $(6 \%)$, while the indices of fertilizer were in the orders of Northeast China (40\%)>
East China (36\%) > North China (9\%) $>$ Central and Southwest China (6.8\%). The indices of annual mean temperature were positive for Central and Southwest China (72\%) and East China (39 \%) but negative for Northeast China (-15\%) and North China ( $-16 \%)$ as shown in Table 2. The indices of annual rainfall were generally lower (Tables 1 and 2). The most important factors influencing yields were identified as follows, soil-related factors ( $90 \%$ ) for North China, both soilrelated factors $(67 \%)$ and fertilizer $(40 \%)$ for Northeast China, both annual mean temperature (39\%) and fertilizer (36\%) for East China, and annual mean temperature (72\%) for Central and Southwest China (Table 2). Based on the analysis results, regional nutrient management strategies can be suggested accordingly (see Table 2). For instance, recommendations for North China, reduced-fertilizer inputs and/or soil-based nutrient management, are highly recommended due to little yield response to increased fertilizer inputs. For Northeast China, balanced-nutrient inputs are recommended to further enhance soil productivity. For East China, organic-fertilizer inputs and/or crop residue return are recommended to enhance soil fertility. For Central and Southwest China, seasonal response nutrient management and/or split-fertilizer application are recommended to reduce nutrient loss and improve fertilizer-use efficiency. 
Table 2 Relative contributions of yield-influencing factors, including soil-related factors, fertilizer rate, annual rainfall, annual mean temperature, and year-time variable in North China, Northeast China, East China, and Central and Southwest China, based on the statistical models (equations in Table 1), averaged over 1992-2012, and recommendations for regional nutrient management strategies based on the identified regional major yield-influencing factors

\begin{tabular}{|c|c|c|c|c|c|}
\hline \multirow[t]{2}{*}{ Regions/major factors and suggestions } & \multicolumn{5}{|c|}{ Relative contributions of factors influencing yields (\%) } \\
\hline & Soil-related factors & Fertilizer use & Annual rainfall & Annual mean temperature & Year-time variable \\
\hline North China & $90.3 \pm 9.6$ & $9.0 \pm 3.3$ & $2.1 \pm 0.8$ & $-15.9 \pm 5.4$ & $14.5 \pm 7.9$ \\
\hline Major factors identified ( $P$ value): & $<.0001$ & NS & NS & NS & $<.0001$ \\
\hline Recommendations/suggestions & \multicolumn{5}{|c|}{$\begin{array}{l}\text { Regional yields were mainly influenced by soil-related factors, probably due to improved soil fertility, but had } \\
\text { little response to increased fertilizer. Reduced-fertilizer inputs/or soil-based nutrient management are highly } \\
\text { recommended }\end{array}$} \\
\hline Northeast China & $67.3 \pm 8.6$ & $40.2 \pm 9.4$ & $2.1 \pm 0.5$ & $-15.4 \pm 3.1$ & $5.8 \pm 3.3$ \\
\hline Major factors identified ( $P$ value $)$ & $<.0001$ & $<.0001$ & NS & NS & 0.02 \\
\hline Recommendations/suggestions & \multicolumn{5}{|c|}{$\begin{array}{l}\text { Regional yields are mainly influenced by both soil-related factors and increased fertilizer inputs. Balanced- } \\
\text { nutrient management, such as balanced NPK ratios and added-organic-fertilizer inputs are recommended to } \\
\text { further enhance soil productivity }\end{array}$} \\
\hline East China & $14.2 \pm 1.3$ & $35.9 \pm 7.2$ & $4.3 \pm 1.8$ & $38.8 \pm 5.3$ & $6.8 \pm 3.9$ \\
\hline Major factors identified ( $P$ value $)$ & NS & $<.0001$ & NS & 0.03 & $<.0001$ \\
\hline Recommendations/suggestions & \multicolumn{5}{|c|}{$\begin{array}{l}\text { Regional yields are positively influenced by both increased fertilizer inputs and annual mean temperature. } \\
\text { Increased-organic-fertilizer inputs /crop residue return are recommended to enhance soil fertility }\end{array}$} \\
\hline Central and Southwest China & $6.3 \pm 0.6$ & $6.8 \pm 1.6$ & $7.2 \pm 2.4$ & $71.5 \pm 4.3$ & $8.1 \pm 4.7$ \\
\hline Major factors identified ( $P$ value) & NS & 0.009 & 0.0005 & $<.0001$ & $<.0001$ \\
\hline Recommendations/suggestions & \multicolumn{5}{|c|}{$\begin{array}{l}\text { Regional yields are mainly influenced by annual mean temperature. Increased temperature conditions not only } \\
\text { can benefit crop growth and nutrient uptake but also influence soil nutrient decomposition and loss. Seasonal } \\
\text { response-nutrient management/or split-fertilizer application are recommended to reduce nutrient loss and } \\
\text { improve fertilizer-use efficiency }\end{array}$} \\
\hline
\end{tabular}

$P$ value probability value, showing significance at $P<0.05 ; N S$ not significant

Climate changes may interact with other factors such as geographic locations, water, and $\mathrm{N}$ availability in affecting crop yield (Trnka et al. 2012). As the above analysis results with multiple linear regressions show, among the major yieldinfluencing factors, the soil-related-factors were more important than both fertilizer use and annual climate variability in rainfall and mean temperature for North China, while both soil-related-factors and fertilizer use were more important than annual climate variability for Northeast China. However, the grain yield for East China was more sensitive to both annual mean temperature and fertilizer use than soil-related-factors, while the grain yield for Central and Southwest China was more sensitive to annual climate variability, especially annual mean temperature, than both fertilizer use and soil-relatedfactors. Kaufmann and Snell (1997) found that climate changes accounted for $19 \%$ of the variation in corn yields for the counties in the US Midwest, while economic-technical changes accounted for $74 \%$ of the variation. Lobell and Field (2007) reported that the temperature and precipitation during the growth period explained $30 \%$ or more of the yearto-year variation in global average yields for the top six widely grown crops. You et al. (2009), using crop-specific panel data to investigate the climate contribution to Chinese wheat yield growth, observed that wheat yield decreased by about 3-10\% for each $1{ }^{\circ} \mathrm{C}$ temperature increase and that a $4.5 \%$ reduction in wheat yields was attributed to rising temperatures over the period 1979-2000, as compared to an increase of $64 \%$ attributable to physical inputs. Studies in Jilin Province in China showed that the contribution of the climate factor to grain yields was $0.21-0.35$, and contribution of the economictechnical factor was $0.65-0.79$, with the amount of fertilizer used being the main factor affecting grain yields and yield changes from 1980 to 2008 (Yao et al. 2011). Liu et al. (2013) observed that warming tended to give larger yield reductions at higher $\mathrm{N}$ fertilizer rates, probably because water shortages resulted from the increased water consumption due to both higher $\mathrm{N}$ and temperature. Clearly, climate is the major uncontrollable factor that influences crop yield, but it is difficult to separate the effect of changes in climate over time from that of other factors such as the increased use of modern inputs and intensified crop management that were introduced during the Green Revolution (Gu 2003). As Asseng et al. (2011) reported, ascribing the yield reduction from warming to higher temperatures alone is misleading without considering the complex impacts and interactions of other factors such as varieties, soil water content, crop management, and rainfall. However, recent studies in China are generally focused on a single aspect of the climate-yield relationships, but ignore the 
interactions of other factors, and the adaptation of farmers to climate change through crop choice and management (Wu et al. 2014). Therefore, region-specific analysis is important in clarifying the trade-offs between agricultural intensification and environment degradation (Yu et al. 2012), as well as climate variability or temporal variability (Girma et al. 2007), to help in developing region-specific fertilizer management practices under varying regional climate conditions.

\section{Conclusions}

This study, based on China Statistical Yearbooks 1993-2013, showed that the increasing trends and differences in regional grain yields in the four regions over the last 20 years were mainly associated with increased fertilizer use over time, especially for Northeast China and East China. However, the fertilizer use increased faster than the increase in grain yields during 1992-2012 for North China, and Central and Southwest China, showing an unbalanced input-output for grain production in these regions. During 1992-2012, regional yield responses to fertilizer use, with regression model coefficients in kilogram per kilogram were in the order: Northeast China (9.3) $>$ East China (5.7) $>$ North China (1.7) $>$ Central and Southwest China (1.2), while the average fertilizer increase rates in kilogram per hectare per year were in the reverse order of Northeast China (1.3) $<$ East China (2.4) $<$ North China (4.8) $<$ Central and Southwest China (6.0).

Based on the statistical models of multiple linear regressions, the indices of relative contributions of the major yieldinfluencing factors to regional grain yields for the period 1992-2012 were estimated, The indices of soil relatedfactors was in the order of North China $(90 \%)>$ Northeast China $(67 \%)>$ East China $(14 \%)>$ Central and Southwest China (6\%), while the indices of fertilizer was in the order of Northeast China (40\%) $>$ East China $(36 \%)>$ North China $(9 \%)>$ Central and Southwest China $(6.8 \%)$. The indices of annual mean temperature was strongly positive for Central and Southwest China (72\%) and East China (39\%), but negative for Northeast China $(-15 \%)$ and North China $(-16 \%)$. Among these indices for the period 1992-2012, the indices of soil-related-factors for North China but both soil related-factors and fertilizer for Northeast China were the highest, while the indices of annual mean temperature and fertilizer for East China but the of annual mean temperature for Central and Southwest China were the highest. Based on the analysis results, regional nutrient management strategies in the four regions are suggested accordingly. For instance, reduced-fertilizer inputs in North China, balanced nutrient management in Northeast China, increased organic fertilizer inputs in East China, and seasonal response nutrient management in Central and Southwest China are recommended.
The results demonstrate an integrative analysis of regional yield-influencing factors, including fertilizer and temporal and climate variability, providing more information to help in developing region-specific nutrient management practices under varying regional climate conditions in China.

Acknowledgments The studies are part of The National Basic Research Program ("973 Program," no. 2011CB100501) financed by the Ministry of Science and Technology of China. The rice field pictures (in Fig. 1) were provided by Professor Zheng Xunhua, State Key Laboratory of Atmospheric Boundary Layer Physics and Atmospheric Chemistry, Institute of Atmospheric Physics, Chinese Academy of Sciences.

\section{References}

Asseng S, Foster I, Turner NC (2011) The impact of temperature variability on wheat yields. Global Change Biol 17:997-1012. doi:10. $1111 / j .1365-2486.2010 .02262 . x$

Eghball B, Varvel GE (1997) Fractal analysis of temporal yield variability of crop sequences: implications for sitespecific management. Agron J 89:851-855. doi:10.2134/agronj1997.00021962008900060001x

Girma K, Freeman KW, Teal R, Arnall DB, Tubana B, Holtz S, Raun WR (2007) Analysis of yield variability in winter wheat due to temporal variability, and nitrogen and phosphorus fertilization. Arch Agron Soil Sci 53:435-442. doi:10.1080/03650340701466754

$\mathrm{Gu}$ L (2003) Comment on "Climate and management contributions to recent trends in U.S. agricultural yields". Science 300:1505b. doi: 10.1126/science. 1083920

Huang S, Zhang WJ, Yu XC, Huang QR (2010) Effects of long-term fertilization on corn productivity and its sustainability in an Ultisol of southern China. Agric Ecosyst Environ 138:44-50. doi:10.1016/ j.agee.2010.03.015

Huggins DR, Alderfer RD (1995) Yield variability within a long-term corn management study: implications for precision farming. In: Robert PC et al (eds) Site-specific management for agricultural systems. ASA, CSSA, and SSSA, Madison, pp 417-426

Kaufmann RK, Snell SE (1997) A biophysical model of corn yield: integrating climatic and social determinants. Am J Agric Econ 79(1): 178-190. doi:10.2307/1243952

Li Y, Conway D, Xiong W, Gao QZ, Wu YJ, Wan YF, Li Y, Zhang SL (2011) Effects of climate variability and change on Chinese agriculture: a review. Clim Res 50:83-102. doi:10.3354/cr01038

Lin T, Xie Y, Liu G, Chen DL, Duan XW (2008) Impact of climate change on crop yields in Heilongjiang province. J Nat Res 23(2): 307-318

Liu YJ, Lin ED (2007) Effects of climate change on agriculture in different regions of China. Adv Clim Chang Res 3(4):229-233

Liu LT, Hu CS, Olesen JE, Ju ZQ, Yang PP, Zhang YM (2013) Warming and nitrogen fertilization effects on winter wheat yields in northern China varied between four years. Field Crop Res 151:56-64. doi:10. 1016/j.fcr.2013.07.006

Lobell DB, Field CB (2007) Global scale climate-crop yield relationships and the impacts of recent warming. Environ Res Lett 2(1):1-2. doi: 10.1088/1748-9326/2/1/014002

Machado S, Bynum ED Jr, Archer TL, Lascano RJ, Wilson LT, Bordovsky J, Segarra E, Bronson K, Nesmith DM, Xu (2002) Spatial and temporal variability of corn growth and grain yield: implications for site-specific farming. Crop Sci 42:1564-1576. doi:10.2135/cropsci2002.1564

Ministry of Agriculture of China (MOAC) (2009) A new round of regional distribution planning of competitive agricultural products (2008-2015). China Agriculture Press, Beijing (in Chinese) 
National Bureau of Statistics of China (NBSC) (1993-2013) China statistical yearbook-1992-2013. China Statistics Press, Beijing (in Chinese)

National Development and Reform Commission (NDRC) (1993-2013) National farm product cost-benefit survey-1993-2013. China Statistics Press, Beijing (in Chinese)

Piao S, Ciais P, Huang Y, Shen Z, Peng S, Li J, Zhou L, Liu H, Ma Y, Ding Y, Friedlingstein P, Liu C, Tan K, Yu Y, Zhang T, Fang J (2010) The impacts of climate change on water resources and agriculture in China. Nature 462:43-51. doi:10.1038/nature09364

Rose MT, Phuong TL, Nhan DK, Cong PT, Hien NT, Kennedy IR (2014) Up to $52 \% \mathrm{~N}$ fertilizer replaced by biofertilizer in lowland rice via farmer participatory research. Agron Sustain Dev 34:857-868. doi: 10.1007/s13593-014-0210-0

SAS Institute Inc. (2004) SAS1 9.1.2 qualification tools user's guide. SAS Institute Inc., Cary

Shi QH, Wang H, Chen F, Chu QQ (2010) The spatial-temporal distribution characteristics and yield potential of medium-low yielded farmland in China. Chin Agric Sci Bull 26(19):369-373

Trnka M, Brazdil R, Olesen JE, Eitzinger J, Zahradnicek P, Kocmankova E, Dobrovolny P, Stepanek P, Mozny M, Bartosova L, Hlavinka P, Semeradova D, Valasek H, Havlicek M, Horakova V, Fischer M, Zalud Z (2012) Could the changes in regional crop yields be a pointer of climatic change? Agric For Meteorol 166-167:62-71. doi:10.1016/j.agrformet.2012.05.020

Wang XB, Cai DX, Hoogmoed WB, Oenema O (2011) Regional distributions of nitrogen fertilizer use and $\mathrm{N}$-saving potentials for improvement of food production and nitrogen use efficiency in China. J Sci Food Agric 91(11):2013-2023. doi:10.1002/jsfa.4413
Wu WB, Verburg PH, Tang HJ (2014) Climate change and the food production system: impacts and adaptation in China. Reg Environ Chang 14:1-5. doi:10.1007/s10113-013-0528-1

Xin LJ, Li XB, Tan MH (2012) Temporal and regional variations of China's fertilizer consumption by crops during 1998-2008. J Geogr Sci 22(4):643-652. doi:10.1007/s11442-012-0953-y

Xiong W, Holman IP, You L, Yang J, Wu W (2014) Impacts of observed growing-season warming trends since 1980 on crop yields in China. Reg Environ Chang 14:7-16. doi:10.1007/s10113-013-0418-6

Yao ZF, Yang F, Liu XT, Yan MH, Meng J (2011) Quantitative assessment of impacts of climate and economic-technical factors on grain yield in Jilin Province from 1980 to 2008. Chin Geogr Sci 21(5): 543-553. doi:10.1007/s11769-011-0493-x

Ye L, Xiong W, Li Z, Yang P, Wu W, Yang G, Fu Y, Zou J, Chen Z, Van Rans E, Tang H (2013) Climate change impact on China food security in 2050. Agron Sustain Dev 33:363-374. doi:10.1007/s13593012-0102-0

You LZ, Rosegrant MW, Wood S, Sun DS (2009) Impact of growing season temperature on wheat productivity in China. Agr Forest Meteorol 149:1009-1014. doi:10.1016/j.agrformet.2008.12.004

Yu QY, Wu WB, Yang P, Li ZG, Xiong W, Tang HJ (2012) Proposing an interdisciplinary and cross-scale framework for global change and food security researches. Agric Ecosyst Environ 156:57-71. doi:10. 1016/j.agee.2012.04.026

Zhang TY, Huang Y (2012) Impacts of climate change and inter-annual variability on cereal crops in China from 1980 to 2008. J Sci Food Agric 92:1643-1652. doi:10.1002/jsfa.5523

Zhou JM (2013) Protection of arable land resources and increase of soil productivity in China. Bull Chin Acad Sci 28(2):269-274 